\title{
Can Text Messaging Influence Perceptions of Geographical Slant? A Replication and Extension of Schnall, Harber, Stefanucci, Proffitt (2008)
}

\author{
Mufan Luo ${ }^{1}$, Angela Falisi ${ }^{2}$, and Jeffrey Hancock ${ }^{1}$ \\ ${ }^{1}$ Department of Communication, Stanford University \\ ${ }^{2}$ U.S. Department of Health and Human Services, Washington DC, United States
}

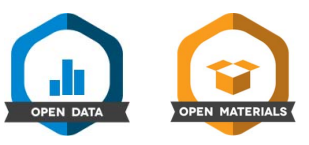

Visual perceptions of the physical environment may be affected by individuals' sense of their psychosocial resources, such as social support. In the original research, Schnall et al. (2008) found that social support can be activated through the physical copresence of a friend (Study 1) or through imagining a supportive relationship (Study 2). The present research aims to replicate and extend this research in the context of computer-mediated communication. In a 2 (social support: high vs. low) $\times 2$ (activation: virtual vs. physical) between-subjects quasi-experiment, data revealed that perceptions of a slant decreased when being accompanied by a friend compared to staying alone and also when texted messaging to a friend compared to a stranger. Moreover, participants texting to a friend reported lower slant estimation than those copresented with a friend. This research replicates the effect of social support on a geographical slant and demonstrates that social support activated through text messaging can influence perceptions even more powerfully than in-person support. We introduce the Hyperpersonal Model to provide potential mechanisms for the intensified effect of virtual support.

Keywords: social support, text messaging, physical challenge, replication

Supplemental materials: https://doi.org/10.1037/tmb0000031.supp

The physical world is filled with burdens and challenges (e.g., a steep hill, a long walking distance, a heavy box). Perceptions of spatial layout in the physical environment reflect one's perceived demand navigating the environment, which is often shaped by both physiological or bioenergetic resources (Guillory, 2013) (e.g., physical

Action Editor: C. Shawn Green was the action editor for this article ORCID iD: Mufan Luo (D) https://orcid.org/0000-0003-0762-9058. No competing financial interests exist.

OSF link: https://osf.io/cf4u5/?view_only=221b1c75275b424685ad428f 54956dc6

Open Science Disclosures:

In The data are available at https://doi.org/10.17605/OSF.IO/CF4U5

3. The experiment materials are available at https://doi.org/10.17605/OSF .IO/CF4U5

Open Access License: This work is licensed under a Creative Commons Attribution-NonCommercial-NoDerivatives 4.0 International License (CC-BYNC-ND). This license permits copying and redistributing the work in any medium or format for noncommercial use provided the original authors and source are credited and a link to the license is included in attribution. No derivative works are permitted under this license.

Disclaimer: Interactive content is included in the online version of this article.

Contact Information: Correspondence concerning this article should be addressed to Mufan Luo, Department of Communication, Stanford University, Building 120, 450 Serra Mall, Stanford University, Stanford, CA 94305, United States. Email: mufanl@ stanford.edu burden, age, fatigue, blood glucose) (Bhalla \& Proffitt, 1999; Schnall et al., 2010) and psychosocial resources such as social support. For example, Schnall et al. (2008) revealed that both the presence and the recall of a supportive relationship can diminish one's perception of a hill's slant when burdened with a heavy backpack.

Digital technology has significantly shaped how people connect with each other in modern society. A prominent type of social interaction is computer-mediated communication (CMC), which refers to text-based interaction in dyads or groups, such as emails, social media posts or comments, and online discussion communities. Of various forms of $\mathrm{CMC}$, text messaging has surged in popularity since its emergence (Anderson, 2015). Decades of research has shown that $\mathrm{CMC}$ has been a valuable resource for people seeking and providing social support, with unique benefits relative to face-toface interaction (FtF; see Rains \& Wright, 2016, for a review). But can text messaging provide social support resources to buffer against physical burdens, such as reducing the perception of a hill's slant?

While the present research aims to examine the reliability of evidence in Schnall et al. (2008) by conducting a replication of their Study 1, a more important goal is to investigate a conceptual extension of the impacts of social support. In light of the Hyperpersonal Model (Walther, 1996; Walther et al., 2015), a theory in the field of communication, that describes how technologies like text messaging can influence social perceptions, we extend their original work by also examining whether or not social support, manipulated by text messaging to a friend, can affect slant perception, and to explore the potential intensified effect of text messaging relative to physical copresence. 


\section{Perceptions of Physical Environment and Social Support}

Individuals' perceptions of spatial layouts, such as geographical slant of a hill, distance to a target, and height of a balcony, not only depends on the actual environment's geometry but also relates to the costs required to act in the environment, which are often shaped by people's capacity to navigate the environment (Proffitt, 2006). This so-called "economy of action" theory is reasoned to account for steeper perceptions of a hill's slant among people in older age, declining health, and with a heavy backpack (Bhalla \& Proffitt, 1999; Proffitt et al., 1995), and for the association between a fear of falling and greater perceived height of a balcony (Stefanucci et al., 2005). In testing the theory, Schnall et al. (2010) also showed that body's metabolic energy, as manipulated by the glucose level, can affect perceptions of geographical slant, such that people drinking sugar-contained juice perceived the hill's slant to be less steep than those without sugar consumption.

Psychosocial resources can also affect perceptions of the physical environment. The Resources and Perception Model (RPM; Harber et al., 2008) argues that psychosocial resources, such as social support, self-esteem, feelings of control, and emotional disclosure, can temper stress and threat induced by challenging objects or negative events, and thus reduce distorted perceptions of the objects, including physical environment (Harber et al., 2008). For example, compared to people who failed to self-affirm core values, people who affirmed the values rated the balcony height as lower while experiencing ego threats (Huynh et al., 2014), and estimated the distance to the landmark as farther away while wearing a heavy backpack (Shea \& Masicampo, 2014). People with negative self-worth perceived their distance to a threatening object (e.g., a live tarantula) closer than the distance to an innocuous object (e.g., a cat toy; Harber et al., 2011). These intrapersonal processes can affect visual perceptions through psychological benefits available to temper stress.

Social support involves the perceived and actual support gained from personal affiliations. It is well established in the literature that social support plays an important role in both physical and mental health, such that it can protect against stress-related illness like common cold, coronary heart disease, and cancer (Cohen et al., 2003; Lett et al., 2005), and reduce pain experience (Brown et al., 2003; Guillory et al., 2015). Furthermore, social support is shown to buffer people from negative physiological and psychological effects of stressful events (e.g., Cohen \& Hoberman, 1983; Cohen \& Wills, 1985; Kaplan et al., 1977). Depleting social support resources, on the other hand, can amplify one's perception of negatively arousing objects (Harber et al., 2008; Study 1).

From the perspectives of the economy of action theory and RPM, social support can provide psychosocial resources available to navigate the physical environment, thereby influencing visual perceptions. In a seminal set of studies, Schnall et al. (2008) recruited passersby either walking with a partner or alone. Participants in naturally occurring walking pairs perceived the hill's slant as less steep than those not in pairs (Study 1). In Study 2, participants imagining a positive relationship perceived the slant to be less steep than those imagining a negative or a neutral relationship, which they reasoned that it was not mere presence (social facilitation; Zajonc, 1965) but the quality of supportive relationships that led to reduced perceptions of a hill's slant. A recent study also showed that people who imagined lifting a heavy box with a friend together perceived the weight to be lighter than those who imagined lifting the box alone (Doerrfeld et al., 2012). Thus, social support as a psychosocial resource can diminish perceptions of challenging stimuli.

Why might this positive effect of social support occur? A prominent proposed mechanism is a cognitive appraisal, referring to the process where people reevaluate their abilities to overcome a challenge in response to the availability of social support (Lazarus \& Folkman, 1984). Social support can restore the perceived capacity to act when a threat is experienced, thereby influencing psychophysical perception (Harber et al., 2011). Furthermore, felt understandingthe feeling of being accurately understood by communication partners-may be another potential mechanism (Oishi et al., 2013). Social support may elicit a default assumption of being understood, which can save people's cognitive resources needed for the task at hand. Finally, "load sharing"- the ability to offload work to the social network, is believed to account for the effects of psychosocial resources on perceptions (Beckes \& Coan, 2011). Social support implies that individuals can offload problems to supportive relationships, which in turn, can reduce the overall cost of navigating to the environment. Therefore, social support may provide a variety of psychological benefits to overcome physical challenges and to reduce the perception of physical burdens.

\section{Can Text Messaging Activate Social Support?}

Schnall et al. (2008) revealed that social support as a psychosocial resource can be activated through simply imagining a supportive relationship, even in the partner's physical absence (Study 2). One key consideration of the current research is whether text messaging a friend can provide the stress-attenuating buffer as well. Prior work has shown that social surrogates and symbolic social connections (e.g., a photo of a friend, thinking of a friend, interpersonal touch) can activate associated mental representations of the presence of a supportive companion, which is sufficient to attenuate physical pain and reduce psychological reactance to stressors (Fitzsimons \& Bargh, 2003; Jakubiak \& Feeney, 2016; Master et al., 2009; Mikulincer \& Shaver, 2001; Smith et al., 2004). Here, we examine whether sending a text message to a friend can activate social support.

Computer-mediated communication such as email, instant messaging, and text-based social media provides valuable means for social support. For example, Guillory (2013) found that participants texting to a friend consumed less high-fat food than those who either texted or saved the message on a computer, suggesting that text messaging can activate social support resources needed to resist unhealthy food. In a clinical setting, text messaging during a surgery led to reduced consumption of analgesic medication compared to playing a distracting video game (Guillory et al., 2015). It is argued that people may perceive text messaging as an opportunity for continued engagement with their social contacts.

However, whether or not this virtual means of social support can provide similar benefits relative to physical copresence is unclear. One possibility is that virtual and physical activations of social support have the same effect. For example, Master et al. (2009), in a cold pressor task, found a similar level of pain ratings among participants holding the partner's hand as those looking at photos. Another possibility is that text messaging to a friend might activate a higher level of social support than the physical presence of a friend. That is because text messaging can bridge the physical distance to allow senders to connect with anyone they feel close to, and thus 
more supportive relationships. Schnall et al. (2008) showed a mediating effect of relationship quality in the effect of social support on slant perception. If this is the case, then social support through text messaging may further distort perceived geographical slant due to the availability of more positive relationships.

The Hyperpersonal Model of CMC (Walther, 1996) provides an alternative account for bolstered social support through text messaging. It argues that the reduced nonverbal cues available in CMC may reallocate people's cognitive resources to the most salient characteristics of the partner that are relevant to the immediate scenario and allow people to form idealized impressions of the person based on these easily accessible features (Walther et al., 2015). This idealization process allows people to form stereotyped perceptions and exaggerated impressions of others because people tend to overattribute the salient social categories about partners based on limited information. Thus, when participants are in need of psychosocial resources, text messaging may draw attention to a partner's helpful qualities and facilitate a more helpful impression about the person than inducing it through physical copresence. In sum, the Hyperpersonal Model predicts an intensification effect of social support through text messaging relative to physically colocated support on a perceived geographical slant.

\section{The Present Study}

The present study is a close replication of Study 1 in Schnall et al. (2008) that aims to examine the effects of social support on perceptions of a hill's slant. To further investigate the effects of symbolic social support as indicated in Schnall et al.'s Study 2, we examined whether text messaging to a friend relative to a stranger can affect perceptions of the slant, and the relative strength of the stress-attenuating effect between text messaging and the physical presence of a friend.

\section{Method}

Raw data and study materials are available at Open Science Framework. All stages of this research were approved by a university IRB.

\section{Participants}

We conducted a priori power analysis using $\mathrm{G}^{*}$ Power to ensure a sufficient sample for this study. Schnall et al. (2008) reported a medium-sized effect of social support on slant perception (i.e., $\eta^{2}=$ .14). A power analysis using this effect size and a significance level of .05 , powered at $80 \%$, required at least 52 participants. On the basis of the original research, we added two conditions about text messaging to the experiment, expecting a significant effect of social support on slant perception in the virtual condition as well. Thus, the total sample size should be at least two times the original $(N=104)$. One hundred and eighteen students $(53.38 \%$ women; age: $M=19.96, S D=2.58$ ) from an East Coast University in the U.S. took part in the study.

\section{Design and Procedure}

A 2 (social support: high vs. low) $\times 2$ (activation: physical vs. virtual) quasi-experiment was employed, which resulted in four conditions: (a) physical—high support $(n=30)$, (b) virtual—high support $(n=31)$, (c) physical-low support $(n=29)$, and (d) virtual-low support $(n=28)$.

We followed the same procedure outlined in Schnall et al. (2008) to manipulate social support. Participants were recruited either individually if they walked alone or in pairs if they walked with an accompanying partner. They were informed that the study was about multitasking behavior and that they would receive a candy bar as compensation. Upon consenting to take part in the study, participants were escorted to the base of a hill, facing toward the hill.

Participants in naturally occurring pairs were all assigned to the "physical-high support" condition (a). Among 15 pairs, 10 were in the same gender ( 8 in male and 2 in female) whereas 5 were mixed in gender. In the first task, they were asked to type a scripted message (i.e., "Hey I am participating in a Comm experiment") in the notepad section of their cell phones, with follow-up questions about their partners. The second task asked participants to assess the hill's slant in their partner's presence. Since both members of a pair were tested, a participant's partner was asked to stand several feet away and to face the opposite direction while the person was participating in the experiment. Participants walking alone were randomly assigned to the other three conditions: "virtual-high support" (b) where they were asked to text the same message to a friend they generally texted the most, and then to estimate the hill's slant; "physical-low support" (c) where they firstly typed the message in the cellphones and then estimated the hill's slant by themselves, and finally "virtual-low support" (d) where they were asked to text the message to an unknown phone number and to report the slant perception.

Using a scripted message rather than allowing participants to create their own messages aims to ensure that any observed effect would not be explained by message content. In addition, typing the same content in cell phones in the physical activation conditions aims to avoid the confounding effect of typing with text messaging.

\section{Measure}

\section{Slant Perception}

Participants judged the slant of the hill both verbally and visually. For verbal estimates, participants reported the hill slant by writing it down on a piece of paper. As a reference, they were told that $0^{\circ}$ represented a flat surface and $90^{\circ}$ represented a vertical cliff. For the visual estimates, participants adjusted a protractor (with degree measurements covered) to match their judgment of the slant.

\section{Relationship Measures}

Participants in the high social support conditions (i.e., text messaging and physical copresence) were asked to report how long they had known the person they texted to or walked with (in months). They also reported feelings of friendliness toward their friend (from $1=$ not at all friendly to $5=$ friendly) and willingness to turn to the person for help with a problem on 5-point Likert scales (from $1=$ not at all to $5=$ absolutely).

\section{Mood}

Participants rated the extent to which they felt happy, anxious, stressed, depressed, angry, and sad on 5-point Likert scales from 
Table 1

Bivariate Correlation Matrix for Key Dependent Variables

\begin{tabular}{|c|c|c|c|c|c|c|c|c|}
\hline Dependent Variable & 1 & 2 & 3 & 4 & 5 & 6 & 7 & 8 \\
\hline 1. Visual estimate & - & & & & & & & \\
\hline 2. Verbal estimate & $.49^{* * *}$ & - & & & & & & \\
\hline 3. Relationship duration & .21 & $-.32 *$ & - & & & & & \\
\hline 4. Friendliness & .09 & -.10 & $.31^{*}$ & - & & & & \\
\hline 5. Helpfulness & .08 & -.02 & .18 & $.54^{* * * *}$ & - & & & \\
\hline 6. Physical condition (general) & -.09 & -.06 & $.29^{*}$ & .03 & .05 & - & & \\
\hline 7. Physical condition (today) & -.04 & -.07 & -.05 & .00 & -.12 & $.20^{*}$ & - & \\
\hline 8. Mood & .14 & -.04 & .10 & -.03 & -.02 & -.08 & -.04 & - \\
\hline Means & 43.23 & 44.15 & 32.72 & 4.59 & 4.48 & 3.18 & 3.07 & 2.01 \\
\hline$S D \mathrm{~s}$ & 10.09 & 11.54 & 50.37 & .56 & .77 & 1.28 & 1.20 & .66 \\
\hline Sample size $(N)$ & 118 & 118 & 61 & 61 & 61 & 116 & 116 & 116 \\
\hline
\end{tabular}

$1=$ not at all to $5=$ a great deal. Ratings were averaged into a composite index of mood after reversely coding for happiness (Cronbach's $\alpha=.80$ ).

\section{Physical Conditions}

Participants rated both the general physical condition and the condition on the day of testing (reverse-coded) on a 6-point Likert scale from $1=$ very poor or unwell to $6=$ excellent .

\section{Materials}

\section{Stimuli}

The hill (29.8 inclination) used for the study is close to the center of the campus with light traffic. Participants judged the hill in all conditions.

\section{Weighted Backpack}

Following the procedure outlined in Schnall et al. (2008), participants wore a weighted backpack during the experiment. The backpack contained hand weights approximating $20 \%$ of the participant's body weight. This amount of additional weight simulates a burden but does not cause discomfort or back strain (Bhalla \& Proffitt, 1999). Since overestimation of hill slants was fairly common even when unburdened (Bhalla \& Proffitt, 1999), the use of a weighted backpack increases overestimation. As described by Schnall et al. (2008), if social support serves as a resource against burdens, then the presence of support should counter the additional burden of the weights. ${ }^{1}$

\section{Results}

\section{Manipulation Check}

Following Schnall et al. (2008; Study 1), we first examined if participants regarded their partners in both physical and virtual space as friends in order to check the manipulation of the presence of social support. Measures of perceived friendliness and helpfulness were used. $62.3 \%$ of participants in the "high social support" condition reported feeling "extremely friendly," whereas $34.4 \%$ reported "very friendly." Similarly, $62.3 \%$ of participants rated their partner as the person they would "absolutely turn to" for help, $24.6 \%$ rated "very much," and $11.5 \%$ selected "somewhat." In addition, one-sample $t$-test showed that participants in the high social support condition considered their partner as friendly, $M=4.59, S D=.56$, $t(60)=22.21, \quad p<.001$ and helpful, $M=4.48, \quad S D=.77$, $t(60)=15.04, p<.001$ significantly more than the middle point of the scale ("moderately"). All bivariate correlations are presented in Table 1. Thus, participants in the high support conditions were either accompanied by or texting to a friend with whom they had a positive and supportive relationship.

\section{Primary Analysis of Slant Estimate}

\section{Visual Measure $^{2}$}

Following the analytical procedure outlined in Schnall et al. (2008), we first conducted a three-way ANOVA (Social Support $\times$ Activation $\times$ Gender) to examine the effects on visual and verbal perceptions of the hill slant (in degrees). Gender was included in the model because previous research indicated that women judged hills to be steeper than men (e.g., Proffitt et al., 1995). This gender difference did not emerge in visual perception (male: $M=42.30, S E=1.24$ female: $M=44.69, S E=1.15), F(1,110)=2.31, p=.13, \eta^{2}=.02$. Neither did it interact with any of the other factors in the model and thus was not reported further for the sake of brevity, $p>.09$.

To examine the effects of social support, activation, and their interaction on slant estimation, a two-way ANOVA was conducted (see Table 2 for descriptive statistics across conditions). The main effect of activation did not emerge in the ANOVA, $F(1,114)=.97$, $p=.33, \eta^{2}=.01$, such that no significant difference of slant perception is observed between virtual and physical activation of support. The ANOVA yielded a significant main effect of social support,

\footnotetext{
${ }^{1}$ There has been an ongoing debate regarding the use of a weighted backpack. This practice has been criticized for imposing experimental demand. Participants, when asked to wear heavy backpacks in the study, may feel encouraged to elevate their slant estimates; this inclination may thus confound the effect of social support (e.g., Durgin et al., 2012; Firestone \& Scholl, 2016). Schnall (2017a, 2017b) disagreed with the proposition by proposing key processes that shape spatial perceptions. The present study aims to replicate Schnall et al. (2008) and thus followed the original procedure.

${ }^{2}$ We identified one outlier 1.5 times the interquartile range below the first quartile of the visual estimate. All findings remained when the outlier was removed from the analysis.
} 
Table 2

Descriptive Statistics of Key Dependent Variables Across Social Support and Activation Types

\begin{tabular}{|c|c|c|c|c|}
\hline \multirow[b]{3}{*}{ Outcomes } & \multicolumn{2}{|c|}{ High social support } & \multicolumn{2}{|c|}{ Low social support } \\
\hline & Virtual (text to a friend) & Physical (copresence) & Virtual (text to a stranger) & Physical (alone) \\
\hline & $M(S D)$ & $M(S D)$ & $M(S D)$ & $M(S D)$ \\
\hline Visual estimate & $36.94(9.28)^{\mathrm{a}}$ & $41.87(8.32)^{\mathrm{b}}$ & $48.18(10.20)^{\mathrm{c}}$ & $46.59(8.89)^{\mathrm{c}}$ \\
\hline Verbal estimate & $42.00(14.56)^{\mathrm{a}}$ & $45.40(11.41)^{\mathrm{a}}$ & $45.46(9.70)^{\mathrm{a}}$ & $43.90(9.73)^{\mathrm{a}}$ \\
\hline Mood & $2.21(.63)^{\mathrm{a}}$ & $1.92(.72)^{\mathrm{a}}$ & $1.98(.61)^{\mathrm{a}}$ & $1.92(.68)^{\mathrm{a}}$ \\
\hline Physical condition (general) & $3.38(1.42)^{\mathrm{a}}$ & $3.40(1.40)^{\mathrm{a}}$ & $3.00(1.09)^{\mathrm{a}}$ & $2.93(1.16)^{\mathrm{a}}$ \\
\hline Physical condition (today) & $3.00(1.25)^{\mathrm{a}}$ & $3.07(1.17)^{\mathrm{a}}$ & $3.43(1.29)^{\mathrm{a}}$ & $2.79(1.05)^{\mathrm{a}}$ \\
\hline Relationship duration & $50.71(63.21)^{\mathrm{a}}$ & $14.12(8.63)^{\mathrm{b}}$ & - & - \\
\hline Friendliness & $4.65(.55)^{\mathrm{a}}$ & $4.53(.57)^{\mathrm{a}}$ & - & - \\
\hline Helpfulness & $4.52(.77)^{\mathrm{a}}$ & $4.43(.77)^{\mathrm{a}}$ & - & - \\
\hline$N$ & 31 & 30 & 28 & 29 \\
\hline Female $(N)$ & 16 & 10 & 19 & 18 \\
\hline Male $(N)$ & 15 & 20 & 9 & 11 \\
\hline
\end{tabular}

Note. Means with different superscripts $(\mathrm{a}, \mathrm{b}, \mathrm{c})$ within a row indicate a significant difference $(p<.05)$.

$F(1,114)=22.26, p<.001$, which is qualified with a significant support $\times$ activation interaction, $F(1,114)=3.71, p=.05, \eta^{2}=.03$.

Pairwise comparisons demonstrated that slant perceptions were lower when receiving a high than a low level of social support when supports were activated through physical copresence, $t(114)=1.97$, $p=.05$, and virtual text messaging, $t(114)=4.70, p<.001$. When the effects of activation on slant perception by social support were examined, participants text messaging to a friend perceived the hill's slant to be significantly less steep than those accompanied by a friend, $t(114)=2.10, p=.04$, Cohen's $d=.04$. On the other hand, text messaging to a stranger did not yield significantly different slant perceptions from standing alone, $t(114)=-.66, p=.51$ (see Figure 1). Results replicated Schnall et al. (2008, Study 1) such that those accompanied by a friend perceived the slant as less steep than those walking alone. Our data further showed that text messaging can activate a greater level of social support than physical copresence to diminish slant perception.

\section{Verbal Measure ${ }^{3,4}$}

The same results for social support and activation were not found when the verbal measure was used. In a three-way ANOVA (Social Support $\times$ Activation $\times$ Gender), the main effect of gender was not significant (male: $M=42.4, \quad S E=1.24 ;$ female: $M=45.8$, $S E=1.52), F(1,110)=2.39, p=.12, \eta^{2}=.02$. In a two-way ANOVA (Social Support $\times$ Activation), neither the main effects nor the interaction effect were significant, $F_{\mathrm{S}}(1,114)<1.35$, $p>.25, \eta^{2}<.01$. The analysis of the verbal estimate was not further reported for the sake of brevity. Thus, we referred to slant estimation and perception as a visual estimate only in the rest of the article.

\section{Potential Mechanisms}

Does relationship duration mediate the effects of social support on slant perception as predicted by Schnall et al. (2008)? Our data showed that relationship duration was not significantly associated with slant perception, $r(59)=-.21, p=.11$, regardless of support activation [[physical: $r(28)=-.05, p=.77$; virtual: $r(29)=-.15$, $p=.42]$. Results were inconsistent with Schnall et al. (2008), although they might result from statistical power being inadequate to detect a small effect.

To test the hypothesis that relationship quality may explain the intensified effect of virtual support on slant perception, we conducted a mediation analysis for relationship duration as a proxy of closeness (Schnall et al., 2008). First, we tested whether our data satisfied the four criteria for mediation by Baron and Kenny (1986). In a set of ANOVAs, we observed a significant effect of activation in predicting visual estimate of slant, $F(1,59)=4.77, p=.03, \eta^{2}=.07$, and relationship duration, $F(1,59)=9.13, p=.004, \eta^{2}=.13$, respectively. Adding relationship duration to the model as a covariate led to nonsignificant effects for both support activation, $F(1,58)=2.89$, $p=.10, \eta^{2}=.05$, and duration, $F(1,58)=.83, p=.37, \eta^{2}=.01$. It indicates that the mediation did not occur. Second, we directly tested whether the mediation effect is significant using the causal inference analysis (Imai et al., 2010). Average causal mediation effects (ACME) of relationship duration mediating treatment effects on slant perception was estimated nonparametrically using the $\mathrm{R}$ package mediation, with 5,000 bootstrapping. The nonsignificant ACME did not provide evidence for a mediating role of relationship duration either $(B=-.81,95 \% \mathrm{CI}[-2.43, .23], p=.14)$.

Furthermore, perceived friendliness was used as a proxy of relationship closeness, and was tested to mediate the enhancing effect of social support. A $t$-test showed that friendliness was not significantly different between text messaging and physical copresence, $t(59)=-.78, p=44$. Causal inference analysis yielded a nonsignificant $\operatorname{ACME}(B=.22,95 \% \mathrm{CI}[-.48,1.39], p=.57)$, which did not support our hypothesis. For exploratory purposes,

\footnotetext{
${ }^{3}$ Eight outliers were observed more than $1.5 \mathrm{IQR}$ below the first quartile or above the third quartile. Results remained when they were removed from the analysis.

${ }^{4}$ We fitted a linear-mixed regression to predict slant perception with the fixed effects of social support, activation, their interaction, and random intercept effects for participants and types of measure (i.e., visual vs. verbal) to assess the robustness of the above findings. $p$ values were computed via the lmerTest package in $\mathrm{R}$ using the Satterthwaite approximation for the degree of freedom. The main effect of social support remained, $F(1,109)=5.29$, $p=.02$, whereas the Support $\times$ Activation interaction effect is only marginally significant, $F(1,109)=3.02, p=.08$. All the other effects were nonsignificant.
} 


\section{Figure 1}

Effects of Activation and Level of Social Support on Perceived Geographical Slant

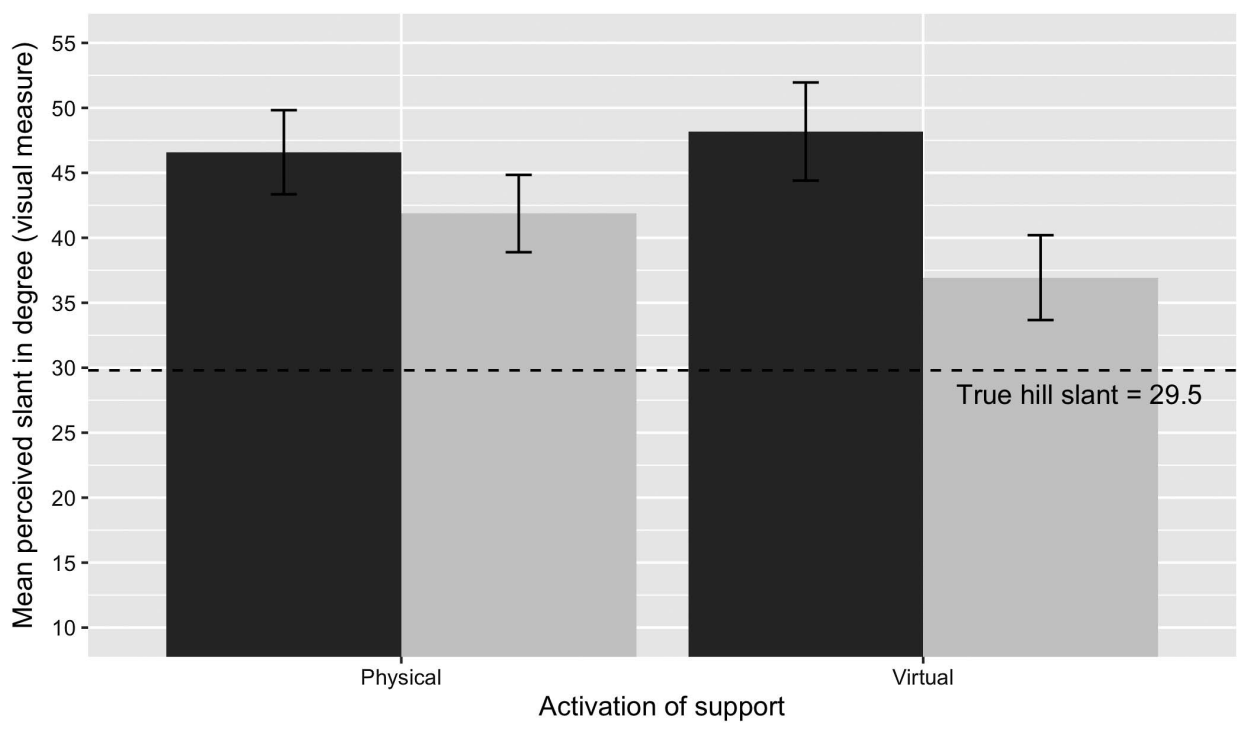

Low social support

High social support

Note. Error bars denote $95 \%$ confidence intervals.

we tested the potential moderating role of perceived friendliness, and found a nonsignificant interaction: Activation $\times$ Duration: $B=.00, S E=.09, p=.99)$ in the regression model.

We also tested perceived helpfulness as a potential mediator of the intensified effect of virtual support suggested by the Hyperpersonal Model. Text messaging did not yield a higher helpfulness rating than physical copresence in a $t$-test, $t(59)=-.42, p=.68$. The causal mediation analysis with 5,000 bootstrapping showed a nonsignificant ACME for helpfulness, $B=.09,95 \% \mathrm{CI}[-.61,1.02]$, $p=.84$, and thus did not provide evidence for helpfulness as a mechanism.

\section{Mood and Physical Ability}

Finally, we examined the roles of mood and physical abilities in slant perception. One-way ANOVAs were conducted to examine if mood and physical ability (today's condition and general condition) differed across experimental conditions. These variables did not significantly differ across conditions [mood: $F(3,112)=1.24$, $p=.30, \eta^{2}=.03$; today's physical condition: $F(3,103)=1.40$, $p=.25, \eta^{2}=.04 ;$ general physical condition: $F(3,112)=1.08$, $\left.p=.36, \eta^{2}=.03\right]$, nor corresponded to the slant perception [mood: $r(105)=-.13, p=.19 ;$ general physical condition: $r(105)=-.08, p=.44$; today's physical condition: $r(105)=-.01$, $p=.88$ ], which were consistent with Schnall et al. (2008). This set of analyses ruled out alternative explanations that the social support effect resulted from individuals' mood and physical abilities.

\section{Discussion}

The present study was a close replication of Schnall et al. (2008; Study 1) which examined the effect of social support on one's perception of geographical slant. We extended Study 2 by examining whether text messaging can activate social support resources to influence perception as effectively as recalling a friend.

Our results replicated the main finding in the original article, such that the presence of physical social support not only reduced the slant perception but also enhanced the perception accuracy (i.e., closer to the true slant). It is worth noting that in addition to the study procedure, our study stimuli-a hill's slant (i.e., $29.8^{\circ}$ )—was also close to the original study (i.e., $26^{\circ}$ ), which makes the present study a convincing replication. In addition, our study demonstrated that text messaging to a supportive contact can activate one's mental representation of social support sufficient to attenuate perceived physical challenge. In sum, data supported Schnall et al.'s (2008) notion that it was not the mere presence of friends but the supportive relationship, activated by text messaging in this case, that affected the hill slant perception. Indeed, alternative explanations such as mood and physical conditions could not account for the effects of social support, as indicated in the original article. Together, these findings demonstrate the robustness of the social support effect: Regardless of how it is activated, social support can attenuate the threats induced by physical challenge, reinforcing the RPM (Harber et al., 2008).

However, our data are only a partial replication of Schnall et al. (2008). First, the effect of social support was only significant for the visual but not the verbal measure of slant perception. It remains unclear why social support did not function for the verbal estimate. However, visual estimates, as measured by adjusting a palm board, have been shown to be more accurate than verbal measures (i.e., self-report the steepness in degree) in both our data and prior work (Proffitt et al., 1995). Second, while relationship duration did not correlate to lower slant perception, it generally followed a nonsignificant trend, which might result from the power inadequate to 
detect a smaller effect size than the initially reported magnitude. It is also possible that relationship duration is not a reliable index of relationship quality, even among undergraduate students. Since we did not include measures about closeness, warmth, and happiness as in Schnall et al. (2008; Study 2), we were unable to examine the roles of relational quality in slant perception, which posed a limitation that future research should address.

It is important to note that one novelty of the current research is an extension of Schnall et al. (2008) by directly comparing the stressattenuating effects between physically and virtually activated support. Our data did not provide direct evidence for two proposed mechanisms. First, neither relationship duration nor perceived friendliness mediates this enhancing effect of text messaging. While CMC bridges physical distance by connecting people to friends whom they had known for longer, texting to an older friend did not explain the intensified decrease in slant perception compared to walking with a newer friend. As discussed earlier, closeness may be a more reliable proxy for relationship quality.

A similar but different explanation is a higher level of perceived helpfulness of the partner activated by text messaging predicted by the Hyperpersonal Model (Walther, 1996). The model posits that the reduced nonverbal and individuating cues in text messaging may lead to an idealized impression and overly positive attributes such as being helpful and supportive. This account would expect an increase in perceived helpfulness in the text messaging condition over the physical condition. This difference, however, may have been muted by a ceiling effect ${ }^{5}$ in the present study.

The fact that text messaging provides more effective support than physical copresence suggests that the simple act of sending a text message can not only activate a mental association with a positive relationship but trigger an attempt to idealize salient features of the person under stress. This Hyperpersonal effect could have psychodynamic implications for the potential intervention for reducing other psychological and physical burdens during stressful and painful events on a daily basis (e.g., Guillory et al., 2015). In real-world situations, when social contact is unavailable, text messaging may lead to even higher social support than in the lab by allowing people to disclose more intimately.

\section{Limitations}

As discussed earlier, one limitation of the present replication research is the lack of data about relationship quality, such as feelings about closeness, warmth, and happiness toward partners. Thus, we could not rule out that relationship quality mediates the effects of virtually activated social support or the enhancing effect of texting. We did not include a haptic measure of the hill's slant, and thus could not investigate if social support can affect visually guided actions. Furthermore, as discussed in Schnall et al. (2008), a full randomization of social support and activation was not achieved in this quasi-experiment because participants who walked in pairs were automatically assigned to the "physically activated high social support" condition. Therefore, we could not rule out all possible individual differences that may have directly affected slant perceptions across the conditions. The issue of nonrandomization was particularly concerning when examining the enhancing effect of text messaging. As we note, this is one of the advantages of being able to text anyone in one's social network compared to accessing those physically present. Nonetheless, it would be useful to tease apart the contribution of relationship duration in support activation by yoking the relationship duration for text-based partners to be the same as the relationship of a participant in the physical condition (e.g., a friend known for 1 year) in a lab experiment. This type of design would allow a more precise analysis of how relationship quality or cognitions about the partner can mediate the effects of support activation on slant estimates.

\section{Conclusion}

We replicated and extended Schnall et al. (2008) by examining how text messaging induces social support resources available to buffer against physical challenges, compared to physical copresence with friends. Consistent with the main findings of the original article, social support, as indicated by walking with a friend and texting to a friend, reduced the perceived slant of a hill. In connection with prior work, our findings suggest that symbolic social connection, such as imagining a supportive relationship, viewing photos, browsing Facebook profiles, and now text messaging, is an effective activation of social support to reduce physical burden or stress. Along with the perceptual idealization that is associated with $\mathrm{CMC}$, this study provides some evidence for why texting may be such a popular phenomenon.

\footnotetext{
${ }^{5}$ Perceived helpfulness (Median $=5$ ) is negatively skewed as a composite measure (skewness $=-1.23$ ), and across activation types (skewness =
} -8.64 for physical activation, skewness $=-1.52$ for virtual activation).

\section{References}

Anderson, M. (2015). For teens, phone calls are reserved for closer relationships. Pew Research Center. https://www.pewresearch.org/fact-tank/2015/ 08/17/for-teens-phone-calls-are-reserved-for-closer-relationships/

Baron, R. M., \& Kenny, D. A. (1986). The moderator-mediatorvariable distinction in social psychological research: Conceptual, strategic, and statistical considerations. Journal of Personality and Social Psychology, 51(6), 1173-1182. https://doi.org/10.1037/0022-3514.51 6.1173

Beckes, L., \& Coan, J. A. (2011). Social baseline theory: The role of social proximity in emotion and economy of action. Social and Personality Psychology Compass, 5(12), 976-988. https://doi.org/10.1111/j.17519004.2011.00400.x

Bhalla, M., \& Proffitt, D. R. (1999). Visual-motor recalibration in geographical slant perception. Journal of Experimental Psychology: Human Perception and Performance, 25(4), 1076-1096. https://doi.org/10.1037/ 0096-1523.25.4.1076

Brown, J. L., Sheffield, D., Leary, M. R., \& Robinson, M. E. (2003). Social support and experimental pain. Psychosomatic Medicine, 65(2), 276-283. https://doi.org/10.1097/01.PSY.0000030388.62434.46

Cohen, S., Doyle, W. J., Turner, R., Alper, C. M., \& Skoner, D. P. (2003). Sociability and susceptibility to the common cold. Psychological Science, 14(5), 389-395. https://doi.org/10.1111/1467-9280.01452

Cohen, S., \& Hoberman, H. M. (1983). Positive events and social supports as buffers of life change stress. Journal of Applied Social Psychology, 13(2), 99-125. https://doi.org/10.1111/j.1559-1816.1983.tb02325.x

Cohen, S., \& Wills, T. A. (1985). Stress, social support, and the buffering hypothesis. Psychological Bulletin, 98(2), 310-357. https://doi.org/10 .1037/0033-2909.98.2.310

Doerrfeld, A., Sebanz, N., \& Shiffrar, M. (2012). Expecting to lift a box together makes the load look lighter. Psychological Research, 76, 467475. https://doi.org/10.1007/s00426-011-0398-4 
Durgin, F. H., Klein, B., Spiegel, A., Strawser, C. J., \& Williams, M. (2012). The social psychology of perception experiments: Hills, backpacks, glucose, and the problem of generalizability. Journal of Experimental Psychology: Human Perception and Performance, 38(6). 1582-1595. https://doi.org/10.1037/a0027805

Firestone, C., \& Scholl, B. J. (2016). Cognition does not affect perception: Evaluating the evidence for "top-down" effects. Behavioral and Brain Sciences, 39, Article e229. https://doi.org/10.1017/S0140525X15000965

Fitzsimons, G. M., \& Bargh, J. A. (2003). Thinking of you: Nonconscious pursuit of interpersonal goals associated with relationship partners. Journal of Personality and Social Psychology, 84(1), 148-164. https://doi.org/ 10.1037/0022-3514.84.1.148

Guillory, J. (2013). Social support, psychosocial resources and eating: Using social media to encourage healthy eating [Unpublished doctoral dissertation]. Cornell University.

Guillory, J. E., Hancock, J. T., Woodruff, C., \& Keilman, J. (2015). Text messaging reduces analgesic requirements during surgery. Pain Medicine, 16(4), 667-672. https://doi.org/10.1111/pme.12610

Harber, K. D., Einev-Cohen, M., \& Lang, F. (2008). They heard a cry: Psychosocial resources moderate perception of others' distress. European Journal of Social Psychology, 38(2), 296-314. https://doi.org/10.1002/ ejsp.448

Harber, K. D., Yeung, D., \& Iacovelli, A. (2011). Psychosocial resources, threat, and the perception of distance and height: Support for the resources and perception model. Emotion, 11(5), 1080-1090. https://doi.org/10 $.1037 / \mathrm{a} 0023995$

Huynh, S., Stefanucci, J. K., \& Aspinwall, L. G. (2014). Self-affirmation counters the effects of self-regulatory resource depletion on height perception. Journal of Experimental Social Psychology, 52, 96-100. https:// doi.org/10.1016/j.jesp.2014.01.003

Imai, K., Keele, L., \& Tingley, D. (2010). A general approach to causal mediation analysis. Psychological Methods, 15(4), 309-334. https:// doi.org/10.1037/a0020761

Jakubiak, B. K., \& Feeney, B. C. (2016). Keep in touch: The effects of imagined touch support on stress and exploration. Journal of Experimental Social Psychology, 65, 59-67. https://doi.org/10.1016/j.jesp.2016.04.001

Kaplan, B. H., Cassel, J. C., \& Gore, S. (1977). Social support and health. Medical Care, 15(5), 47-58. http://www.jstor.org/stable/3763353

Lazarus, R. S., \& Folkman, S. (1984). Stress, appraisal, and coping. Springer Publishing.

Lett, H. S., Blumenthal, J. A., Babyak, M. A., Strauman, T. J., Robins, C., \& Sherwood, A. (2005). Social support and coronary heart disease: Epidemiologic evidence and implications for treatment. Psychosomatic Medicine, 67(6), 869-878. https://doi.org/10.1097/01.psy.0000188393 .73571.0a

Master, S. L., Eisenberger, N. I., Taylor, S. E., Naliboff, B. D., Shirinyan, D., \& Lieberman, M. D. (2009). A picture's worth: Partner photographs reduce experimentally induced pain. Psychological Science, 20(11), 1316-1318. https://doi.org/10.1111/j.1467-9280.2009.02444.x

Mikulincer, M., \& Shaver, P. R. (2001). Attachment theory and intergroup bias: Evidence that priming the secure base schema attenuates negative reactions to out-groups. Journal of Personality and Social Psychology, 81(1), 97-115. https://doi.org/10.1037/0022-3514.81.1.97
Oishi, S., Schiller, J., \& Gross, E. B. (2013). Felt understanding and misunderstanding affect the perception of pain, slant, and distance. Social Psychological and Personality Science, 4(3), 259-266. https://doi.org/10 $.1177 / 1948550612453469$

Proffitt, D. R. (2006). Embodied perception and the economy of action. Perspectives on Psychological Science, 1(2), 110-122. https://doi.org/10 $.1111 / \mathrm{j} .1745-6916.2006 .00008 . x$

Proffitt, D. R., Bhalla, M., Gossweiler, R., \& Midgett, J. (1995). Perceiving geographical slant. Psychonomic Bulletin \& Review, 2, 409-428. https:// doi.org/10.3758/BF03210980

Rains, S. A., \& Wright, K. B. (2016). Social support and computer-mediated communication: A state-of-the-art review and agenda for future research. Annals of the International Communication Association, 40(1), 175-211. https://doi.org/10.1080/23808985.2015.11735260

Schnall, S. (2017a). No magic bullet in sight: A reply to Firestone and Scholl (2017) and Durgin (2017). Perspectives on Psychological Science, 12(2), 347-349. https://doi.org/10.1177/1745691617691948

Schnall, S. (2017b). Social and contextual constraints on embodied perception. Perspectives on Psychological Science, 12(2), 325-340. https:// doi.org/10.1177/1745691616660199

Schnall, S., Harber, K. D., Stefanucci, J. K., \& Proffitt, D. R. (2008). Social support and the perception of geographical slant. Journal of Experimental Social Psychology, 44(5), 1246-1255. https://doi.org/10.1016/j.jesp.2008 .04 .011

Schnall, S., Zadra, J. R., \& Proffitt, D. R. (2010). Direct evidence for the economy of action: Glucose and the perception of geographical slant. Perception, 39(4), 464-482. https://doi.org/10.1068/p6445

Shea, L., \& Masicampo, E. J. (2014). Self-affirmation counteracts the effects of burdens on judgments of distance. Journal of Experimental Social Psychology, 50, 105-108. https://doi.org/10.1016/j.jesp.2013.09.006

Smith, T. W., Ruiz, J. M., \& Uchino, B. N. (2004). Mental activation of supportive ties, hostility, and cardiovascular reactivity to laboratory stress in young men and women. Health Psychology, 23(5), 476-485. https:// doi.org/10.1037/0278-6133.23.5.476

Stefanucci, J. K., Proffitt, D. R., \& Clore, G. (2005). Skating down a steeper slope: The effect of fear on geographical slant perception. Journal of Vision (Charlottesville, Va.), 5, Article 194. https://doi.org/10.1167/5.8.194

Walther, J. B. (1996). Computer-mediated communication: Impersonal, interpersonal, and hyperpersonal interaction. Communication Research, 23(1), 3-43. https://doi.org/10.1177/009365096023001001

Walther, J. B., Van Der Heide, B., Ramirez, A., Burgoon, J. K., \& Peña, J. (2015). Interpersonal and hyperpersonal dimensions of computermediated communication. In S. S. Sundar (Ed.), The handbook of the psychology of communication technology (1st ed., pp. 1-22). Wiley. https://doi.org/10.1002/9781118426456.ch1

Zajonc, R. B. (1965). Social facilitation. Science, 149(3681), 269-274. http://www.jstor.org/stable/1715944

Received March 9, 2020

Revision received January 6, 2021

Accepted January 21, 2021 